\title{
CORONARY INVOLVEMENT IN DISSECTING ANEURYSM OF THE AORTA
}

\author{
BY \\ SAMUEL ORAM AND MARY C. HOLT \\ From the Cardiological Department King's College Hospital \\ Received June 5, 1949
}

Although there are many reports of cases of dissecting aneurysm of the aorta, the number with involvement of the coronary arteries, either deduced from electrocardiographic change or discovered at death, is not great. Shennan (1934) makes no mention of these in his monograph. Also, in the few examples that have been recorded, little attention has been paid to the exact mode of interference with the coronary blood supply. The problem is not without clinical interest, as cases of dissecting aortic aneurysm with long survival are well known. Graham (1886) is usually considered to have recorded the longest period of survival, his patient living for more than thirty years; but the date of formation of the aneurysm is assumed by him to be that on which an internal injury was. sustained. Even after involvement of the coronary arteries the patient may survive for many months.

From a study of the autopsy reports it is apparent that there are several ways in which the coronary blood supply can be rendered inadequate. First, the coronary arteries can be involved in the aortic dissection, which may merely occlude their mouths, or actually extend into and along their walls. Secondly, they can be compressed, either by extravasated blood from the leaking aneurysm, or by the blood of a hæmopericardium. It has been claimed that this blood may distend the pericardial sac, thereby compressing the coronary arteries, or give rise to the formation of percardial adhesions which subsequently exert traction. Thirdly, cases are recorded with cardiographic changes of the type met with in coronary ischæmia, yet without obvious involvement of the coronary arteries. These changes have been considered to result from deficient coronary filling, due to the fall in blood pressure associated with massive hæmorrhage from the dissecting aneurysm. Finally, because atheroma is common in patients with dissecting aneurysm, it is also to be expected that coronary occlusion will, at times, be an incidental event independent of the dissection.

We record below a case showing cardiographic changes in which both coronary arteries were surrounded by extravasated blood derived from the aneurysm.

\section{CASE REPORT}

On the morning of $24 / 12 / 48$ the patient, a man aged 73 , was bending to fasten his shoe when he was seized by a stabbing substernal pain of great severity. This radiated to the lower jaw, through to the back, and down as far as the lumbar region, and across the upper abdomen. The arms were unaffected. This distribution of the pain suggested the presence of a dissecting aortic aneurysm. Sweating and dyspnœa accompanied the pain, which persisted until morphia was administered two hours later. Soon after the onset the patient coughed up about a teaspoonful of fresh blood, and thereafter the sputum was streaked with blood. Vomiting occurred at intervals throughout that day.

By late the same evening he was restless, pale, slightly cyanosed, and sweating. The pulse rate was 86 , the rhythm regular, and the volume poor. No difference could be detected between the 
radial pulses or the femoral pulses. The blood pressure was $95 / 65$ in both arms and there were no signs of congestive failure. The cardiac impulse was impalpable. On auscultation a soft basal systolic murmur was present, but no diastolic murmur or added sounds were heard. CheyneStoke's respiration was accompanied by scattered rhonchi throughout both lungs. Nothing abnormal was found in the abdomen or the central nervous system.

For one year prior to this incident the patient had been aware of increasing dyspnœa on exertion, but had experienced no pain. The family history yielded no relevant information.

On 25/12/48 he was admitted to hospital. By that time he complained only of substernal discomfort, with a sensation of numbness in both arms. An electrocardiogram (Fig. 1) was taken the same day. Standard lead I showed a Q wave of one millimetre depth and slight RS-T segment elevation (less than one millimetre) with inversion of the $T$ wave (minus 1.5 millimetres), there being corresponding slight RS-T segment depression in leads II and III, which also showed some slurring of the QRS complexes. Leads VL and VF closely resembled standard leads I and III respectively. The unipolar chest leads V2 to V6 showed elevation of the junction and RS-T segment, the maximum deviation of the junction being 4.5 millimetres in $\mathrm{V} 3$ and $\mathrm{V} 4$; the $\mathrm{T}$ waves were biphasic $( \pm)$ in V3 to V6, the inversion being greatest in leads V5 and V6; Q waves were absent throughout. No digitalis or other drug likely to affect the $\mathrm{T}$ waves had been administered.
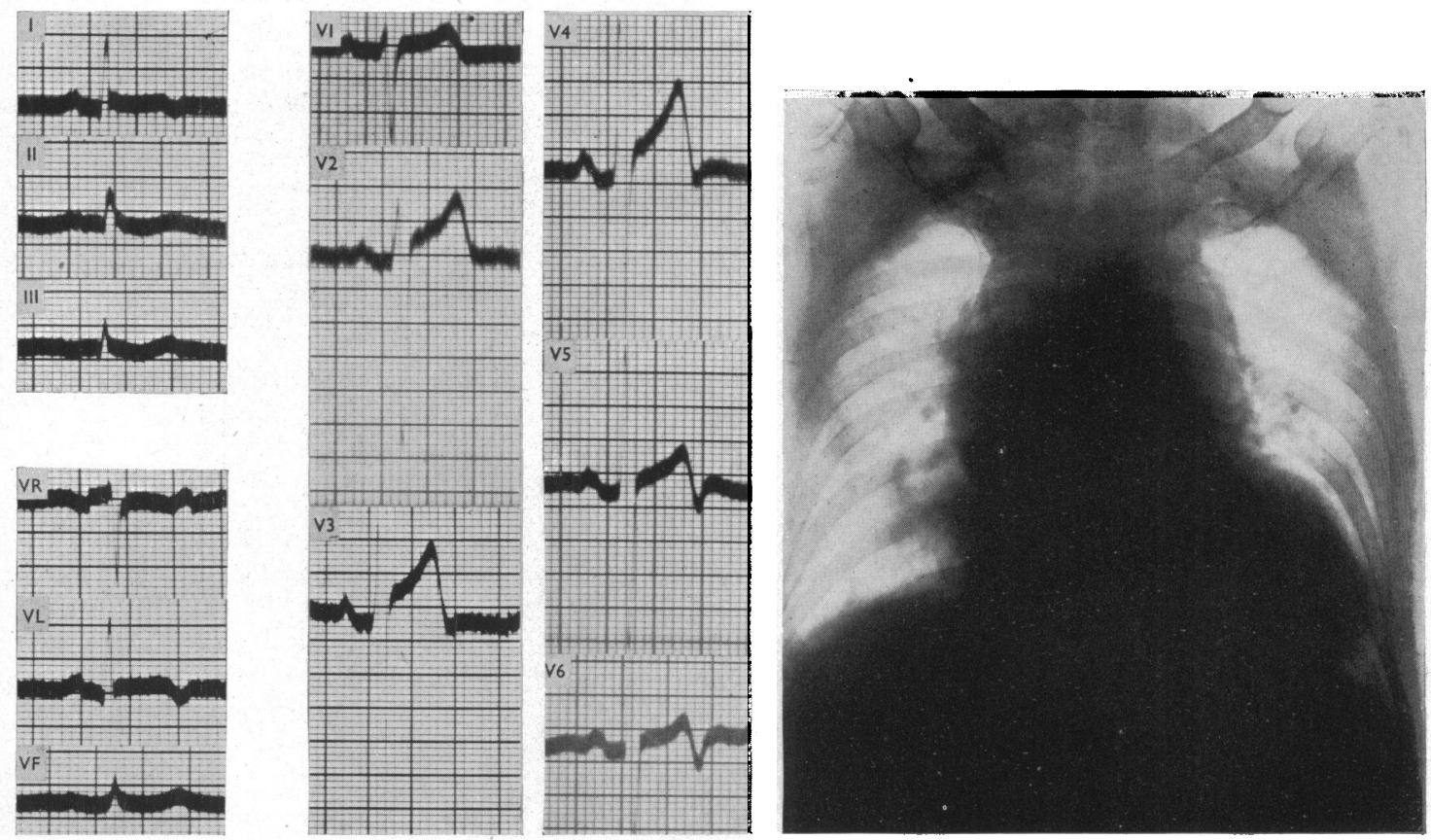

FIG. 1.-Cardiogram showing inversion of the $T$ wave in leads I and VL; elevation of the junction and RS-T segment, and biphasic $T$ waves in leads V3 to V6. The $Q$ waves in leads $I$ and VL are normal and no $Q$ waves

FIG. 2.-Skiagram showing the presence of a large rounded supracardiac shadow which has spread out on each side to obscure the lung apices. are present in the chest leads.

No further pain occurred after admission. The next day the blood pressure had risen to $150 / 80$, and cyanosis and dyspnœa were less evident, but examination of the lungs revealed fine rales at the right base. A portable X-ray of the chest on 26/12/48 (Fig. 2) showed the presence of a large, rounded supracardiac shadow, which had spread out on each side along the line of the first rib to obscure both lung apices. Within the mediastinal shadow, on the left side, a calcified semi-circle was visible, corresponding to the position of the aortic knob. The leucocyte count on 26/12/48 
was 82,000 per cubic millimetre, of which 81 per cent were polymorphonuclear. On $27 / 12 / 48$ the patient was drowsy, and moist sounds were heard in all areas of both lungs. Steady deterioration in his condition followed, and he died later that day.

Necropsy was performed twelve hours after death and showed a dissecting aneurysm of the aorta with hæmopericardium, and primary hypertension with a terminal malignant phase. The aorta was moderately atheromatous. A horizontal tear, $4.5 \mathrm{~cm}$. long, in the aortic arch just posterior to the left subclavian orifice, led into a blood-filled cavity along the right border of the ascending aorta.

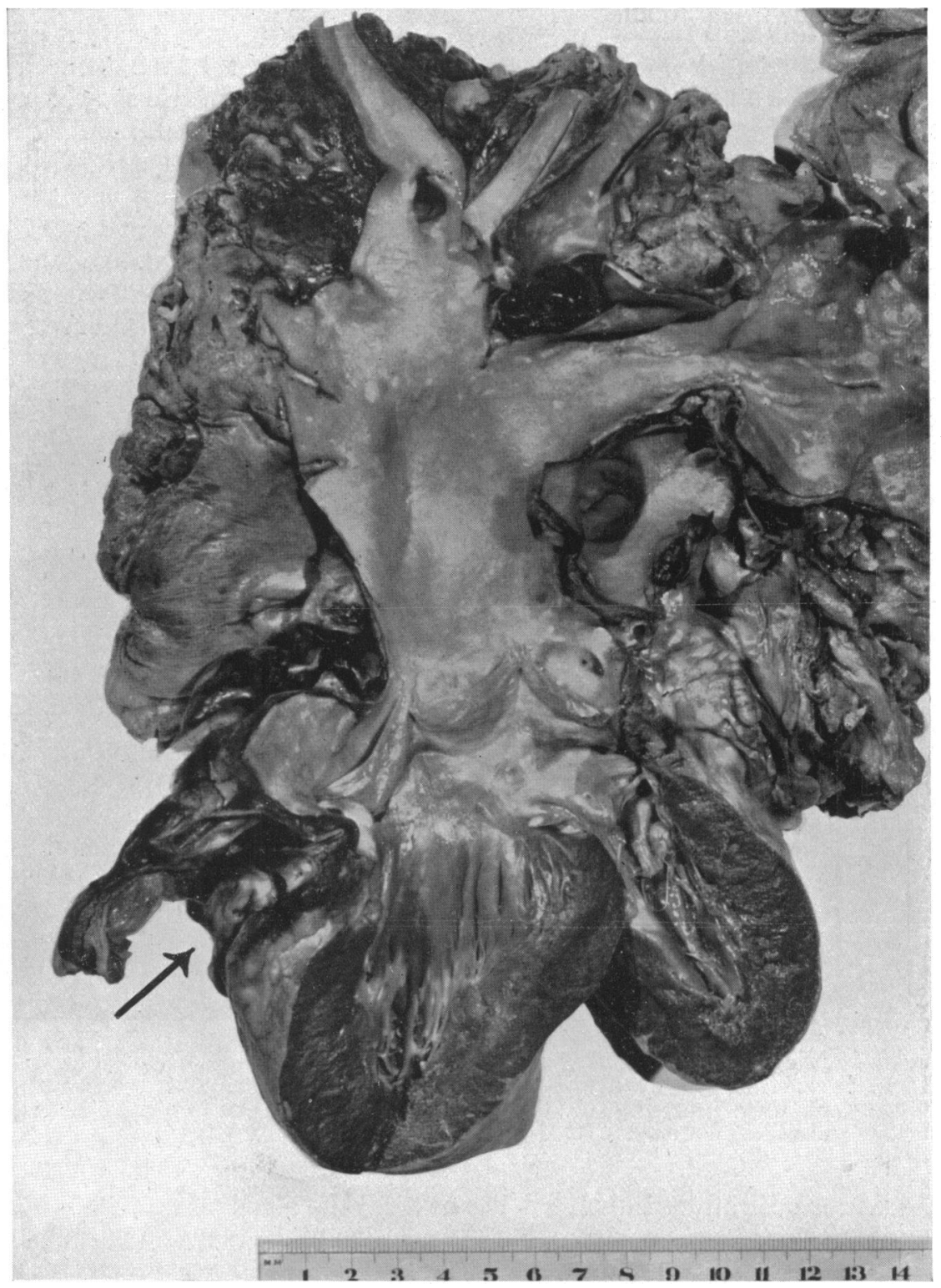

FIG. 3.-The specimen shows involvement by dissection of the innominate, left common carotid, and left subclavian arteries. The arrow indicates the beginning of the left coronary artery which has been laid open. 
Dissection of the wall of the aorta extended from its origin to the diaphragm and involved the innominate, left common carotid, and left subclavian arteries (Fig. 3). There was diffusion of blood along the wall of the left coronary artery and its anterior descending branch for a distance of $4.5 \mathrm{~cm}$. from its orifice (Fig. 4), and along the right coronary artery for $5.0 \mathrm{~cm}$. (Fig. 5). At the time, this appearance was thought to be due to an extension of the dissecting process along the coronary arteries themselves, but subsequent microscopic examination of both arteries showed that the blood lay outside the adventitia in the epicardial fat, the arterial coats being intact (Fig. 6).

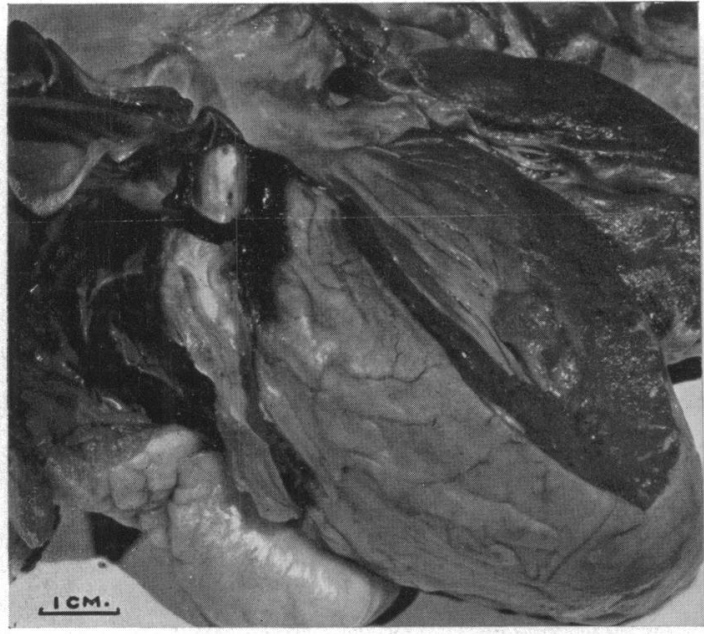

FIG. 4.- Showing extravasation of blood around the first part of the left coronary artery, which has been laid open and is seen running vertically. A piece has been removed for section.

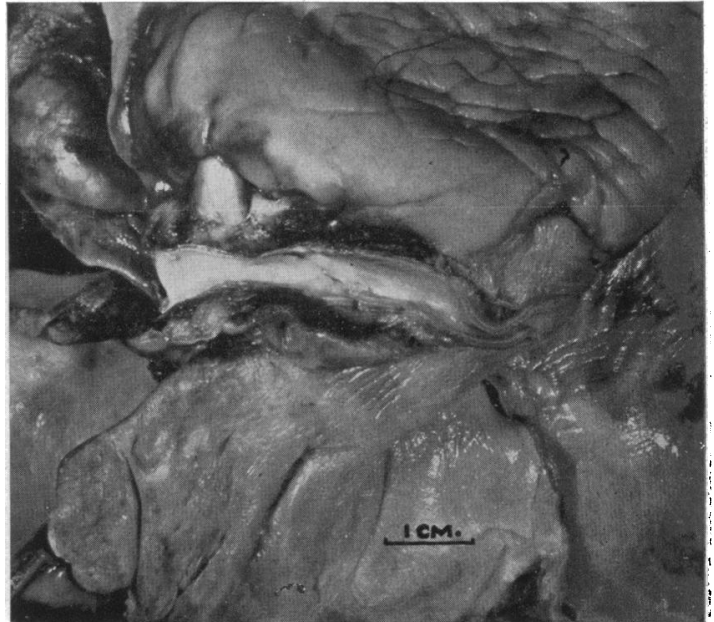

Fig. 5.-Showing blood surrounding the beginning of the right coronary artery, seen running horizontally.

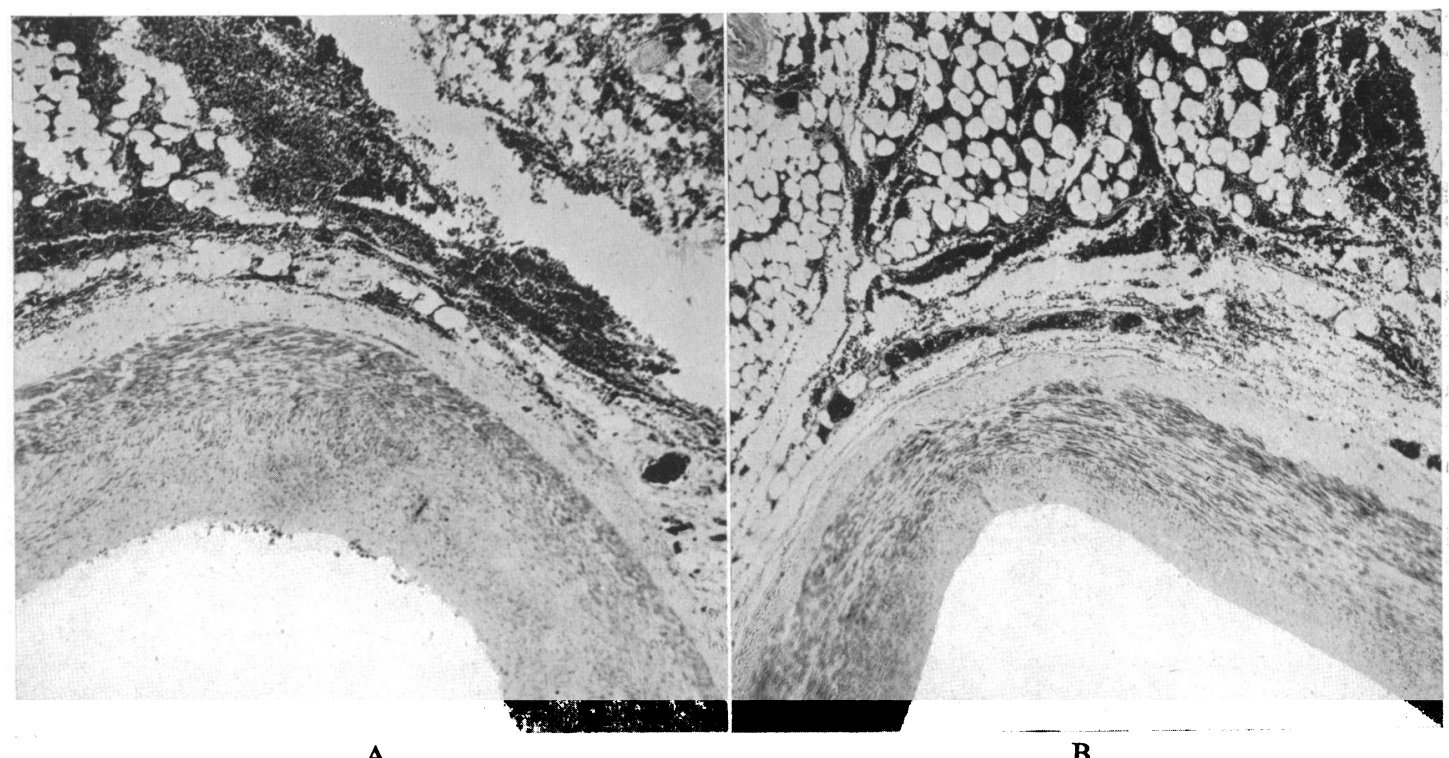

A

Fig. 6.-(A) Left coronary artery. (B) Right coronary artery. Blood is seen to lie outside the adventitia. The: arterial coats are intact. Magnification, $\times 25$. 
Early atheromatous changes were present in both coronary arteries, but there was no evidence of obstruction. There were about $300 \mathrm{ml}$. of fluid blood in the pericardial sac. The heart showed moderate hypertrophy of the left ventricle, but was otherwise normal. The lungs were congested and œdematous, and each pleural sac contained about $600 \mathrm{ml}$. of fluid blood. There was also extensive diffusion of blood into the mediastinum and along the fascial planes of the neck up to the level of the hyoid. The other organs appeared normal with the exception of the kidneys, which showed some narrowing of the cortex. Microscopically, foci of fibrinoid necrosis were found in the capillary loops of many of the glomeruli, and there was severe hyalinization of the arterioles with some medial thickening in the larger vessels. Scattered small areas of hæmorrhage were seen in both cortex and medulla, and some tubules contained red blood corpuscles. Arteriosclerosis was also present in the pancreas and adrenals. These changes were thought to indicate a malignant terminal phase in a previously benign hypertension.

\section{DISCUSSION}

As mentioned above, there are several ways in which the coronary blood flow can be rendered inadequate in dissecting aneurysm. The most obvious of these, but not the commonest, is extension of the aortic dissection to involve the coronary arteries. . Its rarity is probably due, as Wainwright (1944) suggested, to the fact that once the aortic ring has been reached the process is often rapidly terminated by rupture into the pericardial sac. This would also account for the paucity of cardiographic records in these cases. Even when the dissection has reached the coronary arteries it occludes their ostia alone, either one (Glendy et al., 1937; Logue, 1943), or both (Zoints, 1943; Mallory, 1945, 1946, 1947), more often than it involves the coronary artery walls themselves (Pretty, 1931; Glendy et al., 1937; Gardner, et al., 1939; Bayley and Monte, 1943; Wainwright, 1944). In the case reported by Weiss (1938) the aortic dissection occluded both coronary ostia and, in addition, extended for one centimetre along the wall of the left coronary artery; this completely occluded its lumen and a recent infarct was found in the anterior wall of the left ventricle. Actual myocardial infarction is uncommon in these cases of dissecting aneurysm with electrocardiographic evidence of ischæmia. In the case with cardiographic change recorded by Bayley and Monte (1943) the right coronary artery was almost completely occluded by dissection, yet despite this, the myocardium was normal. In fact, the only other case showing infarction was that of Wainwright (1944) in which, again, dissection of the coronary arteries had occurred.

The cases in which interference with coronary blood flow appears to have resulted from compression by extravasated blood in the surrounding tissues fall into two groups. First, there are those in which the perivascular tissues and overlying epicardium are infiltrated by blood from the leaking aneurysm (Hamburger and Ferris, 1938; Reisinger, 1940; Niehaus and Wright, 1941; Sacks, 1945; Halliday and Robertson, 1946). Our own case belonged to this category. Blood surrounding the coronary vessels does not necessarily compress them. In our case, although both coronary arteries. were surrounded, the area of ischæmia was only in the distribution of the left coronary artery, and it is possible that irritation of the vessel wall by surrounding clot may have led to spasm. Secondly, the coronary arteries may at times be compressed by a hæmopericardium. Usually, of course, this is a terminal event and the effects on the cardiogram are not seen, but in two cases (Hardaway and Green, 1935; Steiner, 1945) it was considered that a clotted hæmopericardium had caused obstruction of the left coronary artery, in the first case by pressure of the blood clot, and in the second by the formation of pericardial adhesions. We feel that it is unlikely that the degree of cardiac tamponade could be so great as to compress the coronary arteries yet permit survival of the patient. That pericardial adhesions may form after hæmorrhage into the pericardial sac, and even lead to constrictive pericarditis, is well known, but we doubt very much whether the $T$ wave inversion in such cases is due to traction by the adhesions on the coronary arteries.

Few explanations have been offered to account for the cardiographic changes that may occur in dissecting aneurysm in the group of cases in which no obvious local lesion of the coronary 
arteries is to be found. Bourne and Mills (1946) suggested that possible responsible factors were changes in tension of the aortic wall induced by hæmorrhagic infiltration, mechanical displacement of the heart, and possibly acute necrosis in the myocardium similar to the medial necrosis occurring in the aorta. In support of the last suggestion they cite a case in which the cardiogram showed RS-T segment depression in each of leads I, II, III and IV, changing to left bundle branch block on the day of death, and where focal necrosis of the myocardium was found at autopsy. We feel that this type of case must be rare. If such myocardial necrosis were common, it could scarcely have escaped attention, yet we could find only one other reported case at all similar (Mallory, 1942). Moreover, in both these cases, circumstances were such that compression of the coronary mouths by extravasated blood could have accounted for the findings. Elliot and Evans (1936) attempted to account for this group by suggesting that the cardiographic changes were the result of relative myocardial ischæmia induced by a sudden decrease in the blood volume following hæmorrhage from the aneurysm, in a heart whose coronary arteries were already thickened. In this connection it is interesting to note that we could find only 6 cases in which cardiographic change was present but the dissection was confined to regions distant from the heart, and massive hæmorrhage had occurred in every one of them (White et al., 1934; Osgood et al., 1936 ; Elliot and Evans, 1936; Logue, 1943; Bourne and Mills, 1946). However, it is unusual for severe hæmorrhage to occur before the terminal phase, and in five of these six cases the final cardiogram was taken two or more days before death. But in the sixth case, that of Elliot and Evans (1936), a cardiogram was taken only a few hours before death and showed changes considered to be typical of a recent infarction of the posterior wall. At autopsy no infarct was found and the coronary arteries were patent. Were loss of blood an important factor in the production of the cardiographic changes, similar cardiograms might be expected to result from hæmorrhage and shock from other causes but we could find no example.

The cardiographic changes in dissecting aneurysm are not those typical of cardiac infarction. David et al. (1947) were of the opinion, from a study of their 14 cases, that although no cardiogram could be considered entirely normal, yet changes definitely suggestive of acute myocardial infarction were never present, even in those cases in which the coronary arteries themselves were involved in the dissection. At least two cases are on record with dissection involving both coronary arteries in which the cardiogram remained normal (Mallory, 1946; 1947). The absence of any single cardiographic appearance pathognomonic of dissecting aneurysm has also been stressed (Ritvo and Votta, 1944; Baer and Goldburgh, 1948). In many of the recorded cases the cardiograms are not reproduced. Nevertheless, from a study of the available material certain features stand out which are found in almost all cases. The commonest change would appear to be an elevation of the RS-T segment, usually accompanied by $T$ wave inversion, affecting predominantly either standard lead I or lead III. Another feature in these cases is the absence of $\mathrm{Q}$ waves. This would be consistent with the rarity of actual myocardial infarction already mentioned. A similar absence of Q waves was noted by East and Oram (1948) in their patients with cardiac pain in whom ultimate recovery of the $T$ wave occurred. Presumably in both cases the interference with the coronary circulation is of a reversible nature and is likely to be due to spasm. Yet another feature of the cardiogram in dissecting aneurysm, as illustrated by McGeachy and Paullin (1937), is its lability, striking alteration often occurring in the course of a few days. The case described by Sacks (1945) shows that these variations may not always be as haphazard as might at first appear. Here, the signs of myocardial ischæmia disappeared in the final cardiogram taken on the day of death, and the author suggests that the terminal rupture into the pericardial sac relieved the pressure on the coronary ostia resulting from dissection about the root of the aorta. Perhaps similar factors might account for the terminal diminution in intensity in the cardiographic changes seen in the case described by Bayley and Monte (1943) for here, too, rupture into the pericardial sac had occurred. 


\section{Summary AND CONClUSIONS}

From a study of the reported cases it is seen that interference with the coronary blood supply in dissecting aneurysm can arise in several ways, some demonstrable at autopsy and some conjectural. It can be shown post-mortem to have resulted from the dissection of the aorta occluding the coronary ostia, or extending into the coronary arteries; compression of the coronary arteries from without by blood extravasated from the leaking aneurysm can also be demonstrated at autopsy, as in our case; compression within the pericardial sac by blood clot or pericardial adhesions has been suggested but we feel that this is unlikely; relative myocardial ischæmia has been considered to result from massive hæmorrhage from the aneurysm but, again, we feel that there is no strong evidence in favour of this view; incidental myocardial infarction is also a possibility. Although there are no pathognomonic cardiographic changes, we would draw attention to several characteristic features, namely the absence of abnormal $Q$ waves, the presence of RS-T segment elevation, the transient and often rapidly changing nature of the curves, and the fact that the cardiogram is not typical of acute infarction. Actual infarction is very rare in these cases. Dissection of even both coronary arteries can occur without cardiographic change. We record an example in which both coronary arteries were surrounded by extravasated blood, the cardiogram indicating that the area of ischæmia was limited to the antero-lateral part of the left ventricle.

This problem is of practical interest because it may be most difficult clinically to differentiate cardiac infarction from dissecting aortic aneurysm. The finding of cardiographic changes suggesting involvement of the coronary arteries may add to the difficulties. Fortunately, when the cardiogram that results from involvement of the coronary arteries by a dissecting aortic aneurysm is studied, it is found that, although it differs from that typical of cardiac infarction, it has several features of its own, which should suggest the correct diagnosis.

We are indebted to Dr. Terence East for his helpful criticism of this paper, and we would like to thank also Dr. A. J. Nimmo who referred the patient to one of us (S.O.).

\section{REFERENCES}

Baer, S., and Goldburgh, H. L. (1948). Amer. Heart J., 35, 198.

Bayley, R. H., and Monte, L. A. (1943). Ibid., 25, 262.

Bourne, G., and Mills, P. J. W. (1946). Brit. Heart J., 8, 181.

David, P., McPeak, E. M., Vivas-Salas, E., and White, P. D. (1947). Ann. intern. Med., $27,405$.

East, T., and Oram, S. (1948). Brit. Heart J., 10, 263.

Elliot, A. H., and Evans, R. D. (1936). Amer. J. med. Sci., 191, 196.

Gardner, E., Galbraith, A. J., and Hardwick, S. W. (1939). Lancet, 2, 1019.

Glendy, R. E., Castleman, B., and White, P. D. (1937). Amer. Heart J., 13, 129.

Graham, J. E. (1886). Amer. J. med. Sci., 91, 155.

Halliday, J. H., and Robertson, J. S. (1946). Proc. Roy. Austral. Col. Phys., 1, 3.

Hamburger, M., and Ferris, E. B. (1938). Amer. Heart J., 16, 1.

Hardaway, R. M., and Green, M. M. (1935). Ibid., 10, 384.

Logue, R. B. (1943). Amer. J. med. Sci., 206, 54.

Mallory T. B. (Ed.) (1942). Case Records of the Massachusetts General Hospital, New Eng. J. Med., 226, 828.

- (1945). Ibid., 233, 386.

- (1946). Ibid., 234, 196.

(1947). Ibid., 236, 443.

McGeachy, T. E., and Paullin, J. E. (1937). J. Amer. med. Ass., 108, 1690.

Niehaus, F. W., and Wright, W. D. (1941). J. Lab. clin. Med., 26, 1248.

Osgood, E. E., Gourley, M. F., and Baker, R. L. (1936). Ann. intern. Med., 9, 1398.

Pretty, H. C. (1931). Brit. med. J., 1, 667.

Reisinger, J. A. (1940). Arch. intern. Med., 65, 1097.

Ritvo, M., and Votta, P. J. (1944). Amer. J. Roentgenol, 52, 583.

Sacks, D. R. (1945). Ann. intern. Med., 23, 661.

Shennan, T. (1934). Medical Research Council Spec. Rep. Series No. 193.

Steiner, S. A. (1945). Med. Ann. District Columbia, 14, 155.

Wainwright, C. W. (1944). Bull. Johns Hopkins Hosp., 75, 81.

Weiss, S. (1938). New Eng. J. Med., 218, 512.

White, P. D., Badger, T. L., and Castleman, B. (1934). J. Amer. med. Ass., 103, 1135.

Zoints, M. A. (1943). Texas State J. Med., 39, 375. 